\title{
Model for Monitoring the Professional Activity Efficiency of a Higher Education Teacher
}

\author{
${ }^{1}$ L.N. Kharchenko, ${ }^{2}$ J.P. Gadzhieva, ${ }^{3}$ A.A. Korchinskiy, ${ }^{4}$ A.N. Magomedova, ${ }^{5}$ Y.A. Markaryan, ${ }^{6}$ M.V. Petrova, \\ ${ }^{7}$ G.S. Schelkoplyasova \\ ${ }^{1,7}$ North-Caucasus Federal University, Pushkin Street, 1, Stavropol, Russia \\ ${ }^{2,4}$ Dagestan State Pedagogical University, M. Yaragskogo Street, 57, Makhachkala, Russia \\ ${ }^{3,6}$ South Federal University, B. Sadovaya Street 105, Rostov-on-Don, Russia \\ ${ }^{5}$ Don State Technical University, Gagarin Square 1, Rostov-on-Don, Russia \\ Email: innov_harchenko@mail.ru,d.izieva@mail.ru,korchinski@mail.ru,aika-san@mail.ru,mobilityoffice@mail.ru, \\ yfuftp@mail.ru,shell.26@mail.ru
}

\section{Received: 02 ${ }^{\text {nd }}$ November 2018, Accepted: $28^{\text {th }}$ November 2018, Published: $31^{\text {st }}$ December 2018}

\begin{abstract}
The paper considers and substantiates the original model for monitoring the professional activity efficiency of a higher education teacher. The author's interpretation of this type of monitoring, the description of the methodology for conducting the research and the presentation of its results are proposed. The monitoring model was developed on the basis of a critical analysis of the practice of assessing the efficiency of teachers' activities in universities, which allowed some contradictions and shortcomings to identify in the implementation of this procedure. In contrast to the existing technologies for conducting assessment activities on the part of the subjects - the organizers and participants of monitoring, the author's model includes such important components as the goal and objectives, the object and subject matter, the principles and algorithms of monitoring implementation. The principles on the basis of which the efficiency of a teacher's professional activity should be monitored are openness, objectivity, continuity and cyclicality; science; diagnostic and prognostic orientation, sufficient completeness, relevance. The developed model assumes the algorithms for the implementation of the monitoring process that correspond to the tasks from the selection of monitoring methods and the development of local regulatory legal acts of monitoring to the planning of actions aimed at improving the efficiency of the professional activities of teachers.
\end{abstract}

\section{Keywords}

Model, Monitoring, Efficiency, Professional Activity, Professiogenesis, Higher School Teacher

\section{Introduction \\ 1. Relevance}

The professional activity of a higher school teacher is specific and diverse; it has a pronounced creative and socially oriented character and, therefore, imposes rather strict requirements on the representatives of this profession. A teacher is a functional core of a university's pedagogical system, and the efficiency of this system depends on the efficiency of their activities. Consequently, the level of professional competence of the teacher determines the efficiency and quality of education received by students at the university.

In this regard, it can be assumed that one of the main criteria for evaluating the efficiency of higher education is the highest level of quality of vocational education, which is determined, first of all, by professionalism, i.e. by the willingness and ability to work effectively of scientific and pedagogical workers employed in this socially and economically important area of activity (Kharchenko, 2013).

At present, under the influence of standardization processes, the competence approach in the organization of education dominates in higher education; that gives the student-centered directivity to the process of training, i.e. student is the main object and subject of education. This approach reflects the processes of humanization occurring in higher education. The authors' position towards such an orientation of the educational process at a higher educational institution is that the processes of humanization are possible only with the participation in them of all subjects of the educational process and, above all, teachers, as designers and organizers of training (Petrova, Pivnenko, Kotov et al. 2016).

The authors of the paper adhere to the point of view in which "tracing the logic of the value orientation of the humanistic directivity of higher education, they do not consider a student who masters ready-made knowledge as its center, but a teacher and a student being collaborating people, in the interaction of those who know the world and who look for answers" (Kolesnikov, 1997).

In our opinion, based on the above, the emphasizing the role of a teacher in organizing the functioning of the pedagogical system in higher educational institutions does not in the least contradict the student-centric orientation of higher education. It only points to a teacher as a source of theoretical and methodological, methodological and substantive, psychological and pedagogical foundations of the pedagogical process, and a key condition for quality vocational education (Sakharchuk, 2003; Kharchenko, 2012; Shamova, Tretyakov, Kapustin, 2002; Babaeva, Guljakin, Magomedova et al., 2014).

\section{Factors Causing the Need to Evaluate Activities}


In addition to the above, the analysis of scientific literature (Babayeva, Magomedova, Panova et al., 2012; Panova, 2010; Panova, 2016; Petrova, Pivnenko, Kotov et al. 2016) made it possible to determine that the activities of modern university teachers and administrative approaches to evaluating efficiency of their activities have undergone significant changes, which are expressed in the emergence of the following trends.

The trend of constant updates or innovations is that innovations have become a permanent process of change, which is determined by the laws of the higher education system, which is changing under the influence of political processes, changes in scientific paradigms, requirements of practice, market of educational and research services, etc." (Panova, 2010, 2011).

The trend of evaluating the efficiency of the educational process at a higher education institution is that its efficiency is assessed not so much on the basis of the existing potential of universities, but based on the results of the quality of training and their adaptability in the labor market. The results can be economic, social, pedagogical, scientific, production, what indicates compliance or non-compliance of the quality of training with the requirements of the standard, and the quality of research and development, i.e. the requirements of the customer [Kharchenko, 2013]. In this case, the standard and requirements of the customer of educational and research services are simultaneously considered as entry into the higher education system and exit from it.

"The imperative is the annual analysis and compilation by the federal authority of higher education and science in Russia of a rating of effective universities; this regulates determination of the performance of higher education organizations in the specified system of performance indicators" (Kharchenko, 2013; Babaeva, Gulyakin, Magomedova et al., 2014). By the way, these control procedures entailed the emergence of such a formal regulatory act as an effective contract, which, from our point of view, already contains semantic errors in his title, not to mention some howler, which are entered into its contents by education officials.

Thus, it is necessary to agree that the efficiency of the professional activities of a higher school teacher, with all its specifics, is influenced by many and varied factors that are difficult to account for. Nevertheless, accounting and control of performance as controls are mandatory, since these are strong motivating factors. This statement is supported by the materials of the analysis of currently available scientific, pedagogical, and scientific and psychological literature (Bermus, 2003; Bespalko, 2005; Bordovsky, Nesterov, Tryapitsyn, 2001; Lazarev, 2002; Sankin, Tonkonogaya, 2002). The practice of applying evaluation procedures in various universities has shown that, despite the diversity of approaches in studies devoted to assessing the efficiency of university teachers, the problem has many uncertainties; often the evaluation procedures are not scientifically justified, what makes urgent the task of development of the monitoring model by the authors' team.

\section{Methods}

The content of the various aspects of the problem discussed in this paper was obtained by the authors from various sources and processed using content analysis, which was carried out according to the following logic:

- the study of scientific literature and regulatory documents containing information on the status and organization in educational institutions of Russia of monitoring the performance of professional activities of higher school teachers (more than 20 monographs, theses, articles and several policy documents of the Ministry of Education and Science of Russia were analyzed). In particular, it was found that the directional and systematic studies of monitoring problems were outlined in the national pedagogy in the 80-90s of the 20th century when the works appeared (Bespalko, 2005; Kharchenko, 2014; Shishov, Kalnei, 2000), which were based on the theoretical basis of on education management (Lazarev, 2002, Shamova, Tretyakov, Kapustin, 2002). The publications of these authors identified and disclosed the basic principles and functions of management, and the content of management activities, which laid the foundation for monitoring studies;

- interviewing some teachers (120 people) and education managers of various levels (42 people) who were experts in evaluating various approaches to monitoring the performance of university teachers. Interviewing was carried out in the form of a dialogue on the discussion of issues related to the reflection of forms, assessment procedures and the attitude of experts to the assessment activities being carried out ;

- self-reflection and self-analysis of own subjective long-term scientific, pedagogical and managerial experience of the authors of this paper, who are leaders, employees and teachers in various universities with different orientation of training; - analysis of the results of the survey of university teachers with the help of a specially designed questionnaire, which allows to identify their willingness to change, innovate and to conduct procedures for evaluating their activities. Thus, the results of the study show that the efficiency of the activities of most teachers is unacceptably low, and we consider this fact as an argument in favor of the relevance of the study (Panova, 2010; Kharchenko, 2014).

- statistical processing of the data obtained as a result of interviewing and questioning, for comparing them and determining the significance and prospects of further research on the problem of monitoring the activities of teachers; - discussion and approval by the authors of the text of the paper and, finally, its design.

\section{Results}

Currently, scientists continue to study the issues of education quality management (Bordovsky, Nesterov, Tryapitsyn, 2001; Zagvyazinsky, 2004), approaches and mechanisms of management based on monitoring (Bermus, 2003; Sankin, Tonkonogaya, 2002; Panova, 2010). Scientists, including the authors of the paper (Sakharchuk, 2003; Kharchenko, 2014; Shamova, Tretyakov, Kapustin, 2002; Shishov, Kalnei, 2000) proposed to use productive monitoring models. 
When analyzing primary sources, attention is drawn to the fact that the general context of the problem of monitoring is the boundaries of formal education. But, a very small number of researchers (Zitser, 2007; Babayeva, Magomedova, Panova, 2012) see the solution to the problem of evaluating efficiency by evaluating the results not only in the areas of formal, but also informal activities, beyond the limits of stereotyped individual plans, and also taking into account opinions of students, which indicates an approach in which there are a subjectivity and humanistic principle.

Analysis of scientific sources also suggested that in the conditions of diversification of universities models and the entry of the higher education system into market relations, the efficiency of teachers' professional activity is determined by the state of their readiness for carrying out activity.

Desire of university teachers for self-realization in their professional sphere, which can be expressed as their activity (energy and heightened activity, active state) ultimately determines the efficiency of their type of activity. In this regard, it is appropriate to note that the innovative activity of an university as a whole largely depends on the attitude of teachers to innovations, and the efficiency of mastering any new type of activity by a teacher depends on the degree of development of professional self-organization of a teacher's activity in the space of a constantly developing university.

A survey conducted at several universities in the North Caucasus and Southern Federal Districts showed that more than $90 \%$ of teachers have weakly mastered legal and regulatory framework and conceptual apparatus related to innovation and appraisal activities; teachers have an estrange position in relation to these procedures. Teachers have difficulties in understanding their goals and objectives, choosing the content of innovative and appraisal activities (97\%), in organizing this activity (96\%), in choosing activities (64\%), in assessing their own potential (76\%), in skills to describe, explain, predict their activities (i.e., position themselves) in the market of educational services and intellectual developments (96\%) (Panova, 2010; Kharchenko, 2014);

An analysis of various sources of information carried out by a team of authors (Bermus, 2003; Pulbere, 2006; Panova, 2010) revealed some contradictions and shortcomings of the proposed monitoring technologies (used in the education system). For example:

- in the existing approaches, the quality of education and, consequently, the quality of the teacher's work, is assessed mainly by the results in which the main place is given to their cognitive aspects; the conditions, content and organization of the educational process in which these results were obtained are not always taken into account;

- information on the activities of a teacher collected on the basis of monitoring, in the vast majority of works is mainly quantitative, truncated and insufficient for objective analysis and assessment of the quality of education and the quality of the teacher's work;

- and, therefore, there is a lack of predictive value for such information, and therefore, based on this, it is impossible to make adequate (and effective) management decisions regarding staffing for quality education;

- "the current practice of functioning of internal university quality management systems for training specialists and, often, assessments of the work of teachers are based on an analysis of the current and intermediate monitoring of students' academic achievements in the university in the form of tests and exams; they do not meet the requirements for measurement, do not cover all educational, scientific, innovative and other results of activity and, in general, are not objective enough" (Bermus, 2003; Bordovsky, Nesterov, Tryapitsyn, 2001; Sakharchuk, 2003).

The studies reveal the technological aspects of the implementation of monitoring in the field of education (Bermus, 2003; Pulbere, 2003; Panova, 2016). The results of research of the systematic nature of monitoring, the role of subjects of educational activities in its organization are extremely insufficient; they do not allow to comprehensively considering the professional activities of a university teacher as an object of monitoring. The use of monitoring technologies in relation to assessing the performance of a higher school teacher is, as a rule, not scientifically sound.

In general, the most developed in pedagogical science at present is the problem of selecting the content of education, and the least studied is the management of the pedagogical system, in particular, the management of the quality of education based on monitoring the results of educational activities. The monitoring model proposed by the authors assesses the quality of all components within its scope of activity, including the quality of student learning outcomes.

The identified shortcomings and contradictions actualize the need to develop a model for monitoring the efficiency of the professional activities of a university teacher.

\section{Discussion}

\section{The Purpose and Objectives of Monitoring}

It is necessary to pay attention to the fact that the emergence of the problem on evaluating the efficiency of the activity of university teachers was predictable, since for a number of years the Ministry of Education and Science of the Russian Federation has been monitoring the efficiency of the country's universities. The concept of "effective university" is introduced in the active thesaurus of the Ministry of Education and Science and the educational community. "As far as the evaluation criteria allow: the Unified State Exam, the number of foreign students, the amount of attracted financial resources, the area of classrooms, the employment of graduates and their number registered at the labor exchange, etc., by which the level of efficiency of university is fixed, we can define an effective university as that which meets this criteria system" (Kharchenko, 2013).

It has long been necessary to understand and accept the axiom that a university, its scientific and pedagogical team, students, graduates directly or indirectly influence both the economy and the moral side of society, therefore, their activities should be considered in general form in three interrelated and interacting aspects of efficiency: pedagogical, economic and social. "Therefore, we agree with the definition of an effective institution of higher education as an 
educational organization of higher education achieving high positive effects: pedagogical, economic, social, etc. as a result of its purposeful activity" (Kharchenko, 2014).

The image of an effective higher education institution is created, first of all, by effective teachers who possess not only the skills to teach, but also the qualities of a researcher, manager, marketer, innovator (ibid.). And, only on a secondpriority basis, those who provide the educational process are involved in the image of the university: managers of different levels, educational support staff, technical workers, and accountant department.

These prerequisites, as well as the need to improve the procedure for assessing the activities of teachers in universities, allowed us to develop a monitoring model and give it a scientific interpretation. In the published work, "a model for monitoring the efficiency of the professional activities of higher school teachers is a theoretically created, reasonable, and then is implemented in the university space, a system for assessing the performance of scientific and pedagogical personnel aimed at managing their professiogenesis" (Kharchenko, 2014).

In our study, we understand the monitoring of the professional activity efficiency of higher education teacher as the process of selecting, processing, storing and disseminating information about the educational, scientific, and innovative results of a teacher's activity. This process is focused on informational, organizational, and scientific and methodological support for the management of teacher's professiogenesis and the quality of the educational process at the university at any time, as well as on the forecast of their development and efficiency.

The implementation of the proposed monitoring model allows, on the one hand, monitoring the process of professiogenesis of each teacher, being a condition and criterion for assessing their professional qualities, and also ensures that teachers are involved in management (co-management and self-management) with their own professional growth. On the other hand, it allows teachers to use and develop the reflexive experience of evaluating their own professional achievements to determine the zone of the nearest professional development, and self-designing based on the reflection of experience and identified problems, personalized trajectories of professional genesis, for example, the content of advanced training programs and self-education.

Based on the foregoing and these definitions, the goal of monitoring the professional activity of a university teacher was formulated, which consists not only in determining the efficiency of his/her activities, but, most importantly, in using monitoring in the management of teacher's professiogenesis, and, consequently, in directed changes in the quality of the educational process organization and the quality of training of specialists in high school.

In accordance with the purpose of monitoring, we have defined its tasks which formed the basis for the development of algorithms for organizing and conducting monitoring; in particular, the following actions may be taken:

- Selection of objective monitoring methods and criteria for assessing the results of the teacher's professional activities and their efficiency (not only pedagogical results, but also social, innovation, economic and other activities should be assessed);

- Development of local (intra-university) regulatory acts, scientific and methodological support for the launch and maintenance of monitoring;

- Familiarization of all participants of the monitoring (teachers, students, graduates of past years, employers, specialists of the monitoring service) with the technology of monitoring;

- Testing of the mechanism of advanced control and informing the subjects of monitoring on the results of professional activity and its efficiency;

- Creation of a software product for automated processing of monitoring results;

- Obtaining objective data on the results of the professional activity of a teacher and its efficiency for a certain period;

- The next stage is to obtain objective data on the results of educational, scientific and innovative activities of departments, research laboratories, centers and the university as a whole;

- Creation of a database with results of professional activity of a teacher (department, university) and their dynamics, determination of their rating;

- Determination and development of methods of moral encouragement and charging incentive allowances to teachers' salaries based on the results of monitoring the efficiency of professional activity;

- Identification of positive experience and problem areas in the professional activities of teachers and the study of the reasons for its high or low efficiency;

- Planning actions aimed at improving the efficiency of professional activities and the rating of teachers.

In addition to educational results, it is advisable / necessary to include the results of innovative commercial activities, for example, participation in grant competitions, innovative programs and projects, in the content and procedure for assessing the efficiency of the teacher's professional activities; performance of research, development and technological works; marketing research and the commercialization of scientific and educational products, processes, services; advertising, through participation in science and innovation and educational and innovative exhibitions and showrooms.

In the model proposed by the authors, the subjects of monitoring the efficiency of the professional activities of teachers in addition to the teachers themselves should be current students and graduates of the university of previous years, specialists of the monitoring service, middle-level managers - heads of departments, employees of deans offices and directorates.

Research data shows that when organizing assessment activities, it is necessary to pay attention to the following three positions: "whether the teacher's activities are effective, whether the goals they have set are achieved, and whether these results are obtained with the least possible time, emotional, and psychological costs" (Bespalko, 2005) 
Therefore, the object of monitoring is the professional activities of teachers, its results and efficiency. It is possible that the use of the rating in assessing the activities of scientific and pedagogical personnel, but the study of international and Russian experience, the analysis of the authors' own scientific, pedagogical and managerial experience in using the rating in the management of social and pedagogical systems, indicates that this type of control leads to separateness in research and teaching teams, and does not contribute to the formation of a single creative team.

In our opinion, in the process of implementing the rating, the individual efficiency of each teacher should be evaluated, i.e. dynamic indicators of his/her own growth (the effects of his/her own activities), as a result of his/her own efforts and work on him/herself. This is the most important link of professiogenesis.

It should also be noted that the results of the survey of teachers show that it is more objective and works to form a team to evaluate the work of the department, faculty, institute, especially as teachers are not equally active and effective in various areas of multifaceted professional activity (Stepanov, 2005). In addition, the nature of the activity and, accordingly, its results for humanitarian, public, natural sciences, technical faculties, departments and laboratories are quite different.

\section{Principles of Monitoring}

The introduction of monitoring the performance of university teachers is a psychologically and organizationally delicate process, so it is very important that it be based on principles to avoid misunderstandings and excesses. This is even more important if the individual incomes of teachers are associated with the monitoring results.

According to the authors, among the principles on the basis of which the professional activities of teachers should be monitored, the following should be used:

- Openness (the monitoring procedure, its criteria and results should be open - available to the general public of participants, experts, observers and agreed with them);

- Objectivity (justice, inadmissibility of subjectivity, falsification, juggling, preferences);

- Continuity (a higher education institution is a holistic, dynamically developing system, in this case, both quantitative and qualitative changes over time must be taken into account) and cyclicality (repeatability of monitoring procedures, for example, 1-2 times a year);

- Scientific nature (the monitoring process is based on the laws of management and psychological and pedagogical patterns);

- Diagnostic and prognostic orientation (information obtained in the course of monitoring should be clearly correlated with the previously described normative picture and elaborated criteria, and provide an opportunity to make predictive assumptions);

- Sufficient completeness (procedures, criteria and indicators should be sufficient to obtain objective data on the state of the studied question);

- Relevance (monitoring its algorithms and criteria must comply with the goals and objectives of monitoring, be important and necessary, correspond to the specifics of the teachers' activities).

The function of the monitoring model is to develop, on the basis of a motivational and value-based approach, motivation and form the value sphere of a specialist, his/her settings onto professional growth and self-improvement, the formation of a meaningful attitude towards professiogenesis. In this case, it is necessary to pay attention to the fact that the purposes of assessment and, in general, the philosophy of assessment are changing radically. The assessment procedure with such an approach is not a fixation of results, but a moment of reflection, understanding, followed by an adjustment of the movement trajectory in the space of the pedagogical profession.

Such a model of monitoring and such a look at it can be used to organize the internal university system of continuing education for teachers, and the model can perform various functions, for example:

- Adaptation function - to contribute to the adaptation of a teacher in the professional subculture and activities,

- Target - to adjust the targets of the teacher's professiogenesis,

- Training - to help the teachers to form their own educational field,

- Educating - to form a scientific picture of the world, worldview, personal qualities of the teacher,

- Developing - to contribute to the process of continuous improvement of the professional thesaurus, new skills and competencies,

- Reflective - to promote self-analysis and understanding of their own activities, their quality, to determine the vectors of development in the profession,

- Diagnostic - important for monitoring, contributes to the vision of deficiencies and ways to correct them.

\section{Conclusion}

Thus, having considered some theoretical, methodological and technological approaches to assessing the efficiency of the professional activities of a university teacher based on their monitoring, we can draw the following conclusion.

The proposed type of monitoring is an important element of the management of a modern high school and the professiogenesis of scientific and pedagogical personnel, which performs an effective assessment and prognostic and projective functions.

The authors recommend, when using monitoring, apply both statistical and dynamic types of monitoring procedures. One of them gives an idea and allows analyzing statistics for each of the activities, for example, the number of scientific publications of a teacher per year, compare this number with the standard (the standard level can be determined by the scientific and pedagogical community of the university, taking into account federal requirements, and then fixed in 
employment contract, or performance contract). Another procedure is aimed at tracking the dynamics of indicators, and comparing the obtained data with their own data for previous years, as well as at determining the efficiency of the measures taken to implement the identified deficiencies.

The authors did not manage to overcome the existing procedural complexity of monitoring, which is related to the fact that the results of professional activities of a higher school teacher can manifest themselves throughout the life of a university graduate and the teacher himself.

Another difficulty in monitoring is that the teacher's activities are multidimensional and include such types of work as educational, educational and methodological, scientific, research, innovation (innovative commercial) (Panova, 2010; Kharchenko, 2014), educational and organizational. However, it can be monitored, since all areas (and results) of work have measurable quantitative parameters, which, if necessary and in sufficient quantities, can be translated into qualitative indicators. This direction of research requires further refinement and detailing, adaptation to the conditions of a single institution of higher education.

In general, the results of the study confirmed the assumption that the systematic use of monitoring in assessing the efficiency of the professional activities of high school teachers allows us to gradually move to a new type of management culture (Panova, 2016; Babaeva, Magomedova, Panova, 2012; Petrova, Pivnenko, Kotov and an., 2016), in which administrative management is replaced by socio-psychological methods, in which the increase in the productivity and efficiency of teachers's work is associated with their involvement to the adoption and implementation of management decisions and, consequently, with qualitatively different labor motivation.

\section{Conflict of interest}

The authors confirm that the data presented here does not contain a conflict of interest.

\section{References}

1. Babaeva, E.S., Magomedova, R.M., Panova, I.E. et al. Designing a program of non-formal education and psychological support for a teacher in the first years of work at the university. - Stavropol: Service School, 2012. - 124 p.

2. Babaeva E., Guljakin D.V., Magomedova R.M. end an. 2014. Russian syndromes, impeding the development of the innovation processes in education / Life Science Journal. V.: 11(9s). - P. 184-187.

3. Bermus A.G. Quality management of professional and pedagogical education: extended abstract of Cand. Sci. (Pedagogical) Dissertation. - Rostov-on-Don., 2003. - 44 p.

4. Bespalko V.P. Fundamentals of the theory of educational systems. - Voronezh: VSU, 2005. - 123 p.

5. Bordovsky G.A., Nesterov A.A., Tryapitsyn S.Yu. Quality management of the educational process. - SPb. : Publisher RSPU named after A.I. Herzen, 2001. - 359 p.

6. Zagvyazinsky V.I. Modeling in the structure of socio-pedagogical design / Alma mater. - 2004. - № 9.

7.Zitser D. and N. Practical pedagogy: the alphabet of non-formal education. - SPb. : "Enlightenment", 2007. - 287 p.

8. Kolesnikov L.F. The efficiency of education. - M. : New School, 1997. - 294 p.

9. Lazarev V.S. System development of the school. - M. : Russian Pedagogical Agency, 2002. - 304 p.

10. Panova I.E. The study of the readiness of university teachers to implement innovation / The world of education education in the world. Scientific and methodical journal. - 2010. - № 1 (37), - P. 144-148.

11.Panova I.E. Innovations in education and Russian syndromes / The world of education - education in the world. Scientific and methodical journal. - 2016. - № 2 (62). - pp. 93-98.

12.Petrova N.P., Pivnenko P.P., Kotov S.V. and an. 2016. The Higher School Teacher Matrix of Competences / Social Sciences. V.: 11. - P. 4539-4543.

13. Pulbere A.I. Monitoring system as a means of quality management of continuous technical education: Cand. Sci. (Pedagogical) Dissertation. - Rostov-on-Don, 2006. - 383 p.

14. Sankin L.A., Tonkonogaya E.P. Quality management in humanitarian higher school / Izvestia RAO. - 2002. - № 2. p. 61-73.

15. Sakharchuk E.I. Humanitarian Mechanism of Quality Management for Specialists in Education / Bulletin of Higher Education. Alma mater. - 2003. - №9. - p. 48-49.

16. Stepanov D.V. Effective management: team, hierarchy, autocracy. - SPb.: Speech, 2005. - 144 p.

17. Kharchenko L.N. Arguments in favor of the formation of an effective university model / News of Volgograd State Pedagogical University. Series "Pedagogical Sciences." - 2013. - № 7 (82). - pp. 53-57.

18. Kharchenko L.N. Innovative-commercial activities of a modern university teacher. - M.: Direct-Media publishing house, 2014. - $281 \mathrm{p}$.

19. Shamova T.I., Tretyakov P.I., Kapustin N.P. Management of educational systems: a textbook for students of higher pedagogical educational institutions / edited by T.I. Shamovaya. M.: Humanitarian Publishing Center VLADOS, 2002. $320 \mathrm{p}$.

20. Shishov S.E., Kalnei V.A. Quality of education monitoring school. - M.: Pedagogical Society of Russia, 2000. - 320 p. 